\title{
Toward equity through participation in Modeling Instruction in introductory university physics
}

\author{
Eric Brewe, ${ }^{1,2, *}$ Vashti Sawtelle, ${ }^{2}$ Laird H. Kramer, ${ }^{2}$ George E. O’Brien, ${ }^{1}$ Idaykis Rodriguez, ${ }^{2}$ and Priscilla Pamelá ${ }^{2}$ \\ ${ }^{1}$ Department of Teaching \& Learning, Florida International University, Miami, Florida 33199, USA \\ ${ }^{2}$ Department of Physics, Florida International University, Miami, Florida 33199, USA
}

(Received 9 October 2009; published 20 May 2010)

\begin{abstract}
We report the results of a five year evaluation of the reform of introductory calculus-based physics by implementation of Modeling Instruction (MI) at Florida International University (FIU), a Hispanic-serving institution. MI is described in the context of FIU's overall effort to enhance student participation in physics and science broadly. Our analysis of MI from a "participationist" perspective on learning identifies aspects of MI including conceptually based instruction, culturally sensitive instruction, and cooperative group learning, which are consistent with research on supporting equitable learning and participation by students historically under-represented in physics (i.e., Black, Hispanic, women). This study uses markers of conceptual understanding as measured by the Force Concept Inventory (FCI) and odds of success as measured by the ratio of students completing introductory physics and earning a passing grade (i.e., C- or better) by students historically under-represented in physics to reflect equity and participation in introductory physics. FCI pre and post scores for students in MI are compared with lecture-format taught students. Modeling Instruction students outperform students taught in lecture-format classes on post instruction FCI $(61.9 \%$ vs $47.9 \%, p<0.001)$, where these benefits are seen across both ethnic and gender comparisons. In addition, we report that the odds of success in MI are 6.73 times greater than in lecture instruction. Both odds of success and FCI scores within Modeling Instruction are further disaggregated by ethnicity and by gender to address the question of equity within the treatment. The results of this disaggregation indicate that although ethnically under-represented students enter with lower overall conceptual understanding scores, the gap is not widened during introductory physics but instead is maintained, and the odds of success for under-represented students is not different from majority students. Women, similarly enter with scores indicating lower conceptual understanding, and over the course of MI this understanding gap increases, yet we do not find differences in the odds of success between men and women. Contrasting these results with the participationist view on learning indicates a movement toward greater equity in introductory physics but also indicates that the instructional environment can be improved.
\end{abstract}

DOI: 10.1103/PhysRevSTPER.6.010106

PACS number(s): 01.40.Fk, 01.40.G-, 01.40.Ha

\section{INTRODUCTION}

Recent U.S. public policy [1] reflects the nation's extreme need for increased numbers of science prepared students and teachers. Physics plays a dual role in the development of science students, as first the need in physics is great due to lower enrollments than most other sciences [2], and second, introductory physics is a gateway for most science and engineering majors and is often a roadblock to continued participation in science [3]. Low participation rates by all students in physics are compounded by the overall lack of nonmajority students; enrollments of women, Black, Hispanic, and Native American students in physics are disproportionately low when compared to the other sciences [4]. Thus underrepresentation fails both the discipline of physics, by not providing the broadest diversity of ideas to advance the field, as well as a plurality of students, who miss out on the opportunities provided by an education in physics [5].

Reformed education plays a substantial role in increasing overall participation in physics by establishing instructional practices that support conceptual development by all students. Florida International University (FIU) is a Hispanicserving institution (HSI) with a majority under-represented

\footnotetext{
*eric.brewe@fiu.edu
}

population. By implementing a reformed curriculum and pedagogy, Modeling Instruction (MI), we are working to support all of our students resulting in increased participation in physics by under-represented students contributing to diversification of the population of physicists both locally and nationally.

The Physics Education Research Group at FIU is engaged in extensive efforts to increase the number of historically under-represented students in physics and science, and documenting those efforts with multiple research methodologies. This paper represents one component of an overall study of learning from a participationist framework, including conceptual understanding, retention, persistence, community, affect, and cognitive processes in Modeling Instruction in university physics classes and the surrounding environment. These efforts, originating in the National Science Foundation-funded Center for High Energy Physics Research and Education Outreach (CHEPREO) project, have two primary components: first to establish a supportive classroombased learning environment by implementing MI in several sections of the introductory, calculus-based sequence, and second to establish a broader active learning community among students, faculty, and staff to help integrate students academically and socially into the physics program. The intended outcome of these efforts is increased participation by groups historically under-represented in physics: women, Black, Hispanic, and Native American students. While, the 
needs and histories of these under-represented groups are dissimilar, establishing an inclusive learning environment (reformed courses, supportive faculty interactions, space to foster collaboration) that conscientiously strives to support participation by all students is a sustainable path toward addressing the needs of both the discipline of physics and the physics students themselves [6,7].

\section{THEORETICAL FRAMEWORK}

This paper will first establish a participationist framework on learning, and utilize this framework to examine: (1) the research on historically under-represented groups in physics, (2) Modeling Instruction as a curricular and pedagogical reform, and (3) the impacts of the curricular reforms on students' participation in physics, using both scores on the Force Concept Inventory (FCI) [8] and odds of success in these reformed classes as indicators of participation and equity. These data, taken from over five years of introductory physics courses, show significant positive differences for all students and for all historically under-represented groups in MI when compared with students taught in lecture-format classes on both measures: FCI scores and odds of success. Further analyses of FCI scores reveal understanding gaps based on gender and ethnicity within MI. Analyses of Covariance show that many of the differences for ethnic groups can be attributed to prior academic preparation, but gender differences remain. In contrast to the FCI results, no differences based on odds of success for either gender or ethnicity in introductory physics are found. These results together indicate that issues of equity should be evaluated across broad measures of learning and participation rather than over a single measure. The significance of these results is examined in terms of meeting CHEPREO's overarching goal of creating inclusive learning environments, supportive of historically under-represented students.

\section{A. Reformed instructional practices support all students}

Introductory physics has traditionally been taught through standard, teacher-centered lectures with passive students, assessed almost exclusively by students' problem solutions, and graded using a competitive system (throughout this paper we refer to this form of instruction as lecture format). These practices tend to favor students from the majority [9-11] and lead to a learning environment that isolates students, encourages competition, and does not focus on comprehensive understanding of the content. Reviewing factors that lead to underperformance by Hispanic students, Waxman, Padron, and Garcia [12] identify lecture, drill, and remediation practices as a "pedagogy of poverty," which effectively reduce motivation and enforce low-level skills. Mehan et al. [6] showed that reforms that integrate students of differing preparation levels or "untracking" students substantially increase the continued participation of students considered "at-risk." Reformed instruction, generically, is identified with practices that encourage collaboration among students instead of competition, engage students actively rather than passively, and focus on conceptual development of content over recall [13]. Our goal, then, is to implement appropriate reform curricula that explicitly supports all students while increasing participation of historically under-represented students at a HSI.

Establishing an inclusive learning environment that is supportive of under-represented students requires comprehensive changes across elements of the learning environment, including introductory classes, informal learning environments, recruitment and advising practices, and departmental structures [14]. We acknowledge that reforming the introductory physics classes alone is not sufficient to effect substantial sustainable change. However, the introductory sequence is the first direct experience with the physics department, and by reforming these classes, students are provided with an entry point into a learning environment that fosters learning and participation at the onset of their undergraduate career. Further, reforming the introductory classes serves as an opportunity for faculty and the department to leverage further reforms to the overall learning environment. As a result, we aver the implementation of MI in the introductory sequence has served as the foundation for the creation and fostering of a vibrant learning community, which supports increased participation by our population including a majority of historically under-represented students.

Fostering an inclusive learning environment that encourages participation in science is a complex endeavor, requiring sensitivity to the overall educational context including the practices and norms of the learning community [15]. The impacts of the reforms undertaken in establishing such a learning community are broad. This paper addresses two indicators, FCI scores and odds of success in introductory physics, which together provide a broad view of equity and participation in the reforms. Conceptual understanding as measured by the FCI reflects students' conceptual development in introductory physics, and odds of success in introductory physics reflect the retention of students in introductory physics. Evaluating both the conceptual development and the retention of students together allows us to broadly evaluate how student participation in introductory physics is transformed as a result of the instruction and if these transformations of participation are equitably realized. We support the claim that Modeling Instruction transforms participation by presenting five years worth of comparative FCI data, these data are also disaggregated by gender and ethnicity to establish whether the conceptual development resulting from MI is equitably realized. A second more direct measure of how Modeling Instruction transforms participation by improving retention is the increased odds of success in MI, and disaggregation of these data indicate that the Modeling Instruction environment supports equitable participation of students.

The literature on treatment of both gender and ethnically under-represented groups share common characteristics but are not completely aligned, therefore we acknowledge that effects of treatments for gender and ethnicity are similar yet distinct. However, reviewing the literature on impacts of reform on both gender and ethnicity shows considerable overlap and emerging evidence suggests that incorporating educational reform benefits all students. In one such example, Cabrera et al. [16] identifies two camps of researchers: those 
who consider collaborative learning, which is the cornerstone for many educational reforms, as particularly beneficial to white women and minorities [17-20], and those who view collaborative learning as beneficial for all students [21-23]. Cabrera et al. [16] went on to provide evidence that all students benefit from collaborative learning, which indicates that education reform targeting improved performance by all students is preferable. The primary purpose of the CHEPREO project is to support participation of all students, and the demographics of our population include both ethnic and gender historically under-represented groups. As a result, our treatment and research impacts both under-represented groups.

\section{Instructional practices that support diverse students}

Atwater [6] described effective science education as "aimed at providing equitable opportunities for all students to learn quality science." She identifies teacher-student interactions and orientation of science pedagogy toward reciprocal integration as pedagogical reforms which address equity issues in science. Lynch [24] identified curricular reform toward an explicit, focused, and in-depth curriculum as a key to attending to equity issues in science. In either view of reform, the intent is not to only support under-represented students, but instead to inclusively support all students, creating a sustainable approach that equitably realizes benefits.

Instructional recommendations to support diverse students (pertaining to both gender and ethnicity) abound [12,14,24-26]. Considerable overlap can be found in these sets of recommendations including: (1) cognitively based instruction focused on deep understanding of concepts through use of representations, metacognitive skill, scientific reasoning, and engaging in scientific discourse [27], (2) culturally responsive or congruent instruction, and (3) cooperative group learning emphasizing in-depth conversation among faculty and students. While these recommendations are plentiful, implementations of these recommendations and research supporting the implementation is lacking [28]. Further, these recommendations are primarily directed toward secondary science and ignore university science courses.

\section{B. Learning transforms participation and drives pedagogical and curricular reform}

The implementation of any reformed instructional practice is driven, either explicitly or implicitly, by an underlying view on learning. Common perspectives on how learning occurs vary from transmission to acquisition. However a third perspective views learning as a transformation of participation in a community [29-32]. This third view, the "participationist view," is compelling because it focuses not only on the teacher or the student, but on the complex set of interactions between teacher, students, peers, and others engaged in a shared enterprise, and thus accounts for the context surrounding these interactions $[31,32]$. The most significant outcome of these three perspectives is the design of the learning environment. In the participationist view, students and teachers work in collaboration, the teacher acts as the guide to the students using his or her greater experience and position as a member of the community to help students engage with the tools, practices, and norms of the discipline. Students in the participationist classroom are active and engaged in using the tools to construct a discourse in accordance with the norms of the community [33].

Adopting a "learning as transformation of practice" theoretical perspective influences the curricular and pedagogical choices made in implementing an overall educational reform. The role of the teacher is no longer a sage on stage or even guide on the side, but that of active participant in the learning process providing guidance and experience but also helping to engage all students in the discourses of the learning community. Curricula utilizing this view also should be explicit about the tools, practices, and norms inherent in the discipline and should promote students actively utilizing the tools and engaging in the practices which have motivated the norms of the discipline. When all students are engaged in learning the tools, practices, and norms of a community, it de-emphasizes challenges facing under-represented students, including language issues and perceptions of not fitting the mold of a physicist, as all students must transform their participatory roles. Embracing learning as a means to transformation of participation of students in a discipline enables us to highlight pathways to increased participation in physics while including historically under-represented students in spite of what have traditionally been barriers to participation.

\section{Viewing Modeling Instruction through a participationist framework}

Modeling Instruction is a reform effort that has had great success at the high school level, [34] and which is based on the Modeling Theory of Science [35]. MI shares many features with other reform efforts in physics, including active engagement of students through cooperative groups, emphasis on conceptual development, and use of multiple representational tools, all of which are reported to support underrepresented students. One distinctive feature of MI is that the curriculum, pedagogy, and foundational epistemology are coherently connected to a participationist perspective on learning. MI's origins in the Modeling Theory of Science provide an epistemological foundation that is evident in the curriculum as student activities are focused on the process of building, validating, and deploying models. This process of modeling replicates the central activity of practicing scientists and, therefore, promotes students engaging with the practices and norms of physics [36]. The explicit epistemological foundation of physics as model building and use identifies intrinsically active processes, which in MI are the ontological building blocks of the normative practice of physics. Coherence between the epistemological foundation of MI and the learning as transformation of participation perspective is manifest in the curriculum and pedagogy.

\section{Curricular features of Modeling Instruction align with a participationist framework}

Two of the central features of the Modeling curriculum are aligned with participationist views of learning: modelcentered curriculum organization and the reliance on mul- 


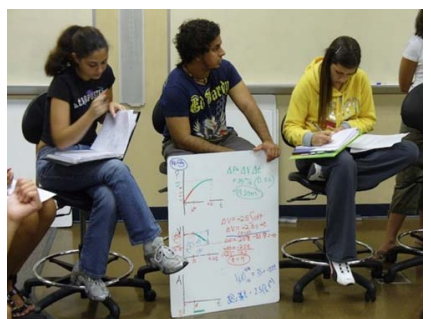

(a)

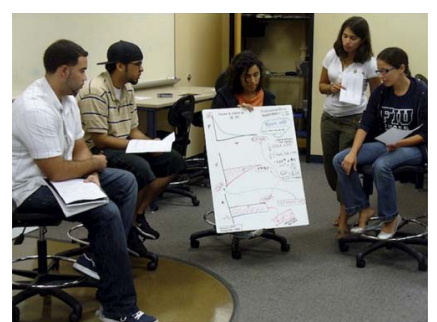

(b)

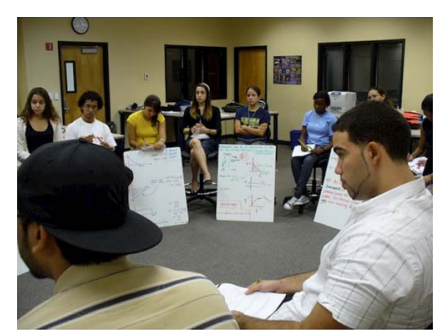

(c)

FIG. 1. (Color) [(a)-(c)] Student participation in model construction. Photo credit: Natan Samuels.

tiple representational tools to create models. The Modeling curriculum is organized around a small set of models in introductory physics, and students in Modeling Instruction are engaged in the creation of these general models and application of the general models to create situation specific models. Making the creation of models an explicit focal point of the curriculum identifies the processes by which knowledge is created and prescribes the forms of students activity that are normative within the discipline. The creation and use of these models is accomplished through the deployment and interpretation of representational tools (inclusive of graphical, formulaic, and verbal representations) which are appropriate to physics. The MI curriculum makes explicit the ways that students are expected to participate in physics by identifying the ontological elements (Models) and the epistemological processes (Modeling). By making these explicit, the Modeling curriculum supports the transformation of participatory roles that students engage in, guiding them toward roles that are coherent with the norms and expectations of the discipline.

\section{Modeling Instruction's pedagogical features enact participationist views on learning}

Modeling Instruction courses at FIU operate as a collaborative learning environment, with 30 students in a studioformat class with integrated laboratory and "lecture." Inquiry laboratories and activities targeting conceptual reasoning and problem solving are the primary vehicles through which models are built, validated, and extended [36]. Model building and use are motivated not only through the activities, but also by the instructors' role in managing discourse in the class. Modeling Instruction courses at FIU utilize Modeling Discourse Management [37], a technique for directing collaborative student-student discourse in a MI environment. Modeling Discourse Management further centers the instruction in student interactions where model-building activities require student collaborative work and sharing through portable whiteboards, but with higher expectation on students constructing their physics knowledge. The instructor's role is to inform students of the norms and practices of physics throughout the course of their discussion and to orchestrate activities which encourage students to engage in appropriate forms of participation and conceptual development. This approach to instruction is designed to foster student participation in the introductory classes in ways which match practicing physicists. (a) Modeling Discourse Management encourages transformation of student participation. The management of student discourse in MI is designed to help students transform the ways in which they participate in the physics class and to mimic the ways that scientists participate in the physics community. Elements of Modeling Discourse Management, which support this transformation of participation, include: deliberate creation of a cooperative learning community, motivating an explicit need for the creation of models in science, expecting student creation of shared interindividual meaning, and interstudent discussion [37]. Drawing on an example of instruction during Fall 2009, we provide a brief example of Modeling Discourse Management.

(b) Instructional example of Modeling Discourse Management highlighting transformation of participation. During the third week of the first semester, the instruction is designed to have students compile constant acceleration models and search for general characteristics of the model. This typical instructional example comes from a single class with 24 students in eight groups of three students. Class begins with each group of three students being assigned the task of creating a specific model of a different constant acceleration physical situation and to summarize the model on a small portable whiteboard. They are given $25 \mathrm{~min}$ to complete the model. During the $25 \mathrm{~min}$, the instructor(s) circulate around the room, visiting each group of students to ask questions or just observe the work. After $25 \mathrm{~min}$ the students gather for a "board meeting" in the front of the room, bringing their whiteboards, chairs, and notebooks and arranging themselves into a large circle. A blank portable whiteboard is placed in the center of the circle with several markers. The instructor begins by asking each group to present the situation and their model of the situation [Figs. 1(a)-1(c)]. During the presentation, groups describe their use of representational tools (motion maps, kinematic graphs, and equations) in modeling the situation and are expected to ask and respond to questioning from their peers. The instructor remains outside of the circle placing the focus on the student-student interaction and interjects to clarify vocabulary, ask for further explanation, or mediate disagreements between students.

After each group has described their model, the instructor moves to the blank board at the center of the circle and asks, "What is similar in all of these models?" This question focuses student attention on a metalevel analysis of all the situations. Students volunteer that certain characteristics are the same, "The slope of the $v$ vs $t$ graph is always constant," for example. As students volunteer this information, the instructor writes it on the whiteboard at the center. After each 
new proposition, the instructor asks the students to either accept or reject what has been written. This proceeds until students have discussed characteristics of all kinematic graphs, motion maps, and equations. The instructor then asks, "What is the same in all of these situations?" Again students discuss, and eventually identify that each situation involves constant acceleration. The instructor then proposes that the list of characteristics of the models would be appropriate for any situation involving constant acceleration. Once the students agree that this seems reasonable, they return to their tables.

This instructional vignette highlights how MI supports student transformation of participation, and is typical of instructional activities across the course. The student activity is based on compiling a model and the instructor has established a situation where students are required to collaborate because they have all solved different problems. In this vignette, the content of the class relies on results of student work to build an appropriate model. The students build the model collaboratively, and it is not accepted until students agree on the elements of the model. Student participation in the classroom community is valued, and the structure of the interaction and discourse reasonably replicates authentic scientific discourse: scientists must construct models that represent aspects of the physical world, these models must be communicated, scrutinized, and accepted as valid within the scientific community. This class meeting is a microcosm of discourse in a physics community, and by enabling and expecting students to participate in the classroom-based, inclusive learning community they learn the underlying lesson that learning involves participation in a discipline community.

\section{How Modeling Instruction provides an inclusive supportive learning environment}

The theoretical framework and motivations of this research project are centered on how MI provides an inclusive and supportive environment for students. Measures of conceptual understanding and odds of success in the introductory physics course indicate how MI establishes an inclusive supportive environment in a HSI. Further, because both conceptual development and odds of success are indicators of how the MI learning environment transforms participation, they also provide an opportunity for us to evaluate the inclusive nature of the learning environment by looking at the equity of outcomes within MI. From this perspective, three research questions underpin this project.

\section{Support of all students}

How does MI support the conceptual development and enhanced participation of all students as indicated by FCI scores and success odds as compared with lecture-format instruction at a HSI?

\section{FCI and equitable participation of under-represented groups}

Do the FCI results indicate an equitable transformation of participation in MI for historically under-represented groups?

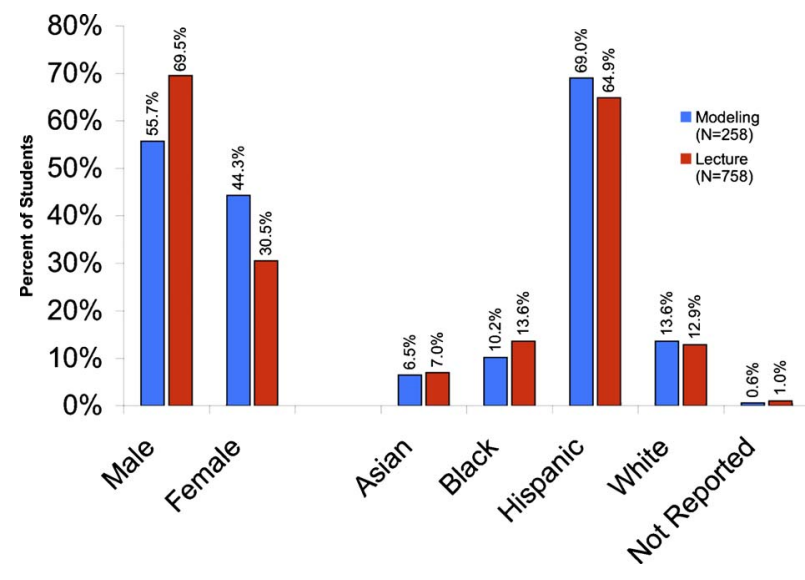

FIG. 2. (Color) Demographics of Introductory Physics, there were ten Native American students in the lecture-format data that are not represented in the chart.

\section{Odds of success and equitable participation of under- represented groups}

Do the odds of success indicate an equitable transformation of participation in MI for historically under-represented groups?

\section{STUDY}

\section{A. Methods}

FIU is the largest source of Bachelors degrees for Hispanic students in the United States [38]. It is an urban, public research university with 38290 students with a Hispanic enrollment of nearly $60 \%$, nearly reflective of local demographics [39]. The two treatments in this study (lecture format and MI) have similar rates of participation in terms of ethnicity, but differ in terms of gender, see Fig. 2. Two characteristics of the student population, the high percentage of females and the majority under-represented students, make this study unique and make FIU an ideal setting for increasing participation of under-represented students, especially Hispanic students, in physics while developing models for improving the educational landscape for all students.

\section{FCI data as indicators of equity and participation}

We measured conceptual understanding with the FCI, a 30 item multiple-choice conceptual test covering Newtonian mechanics and kinematics, topics covered in the first semester of introductory physics [40]. The FCI has been used extensively to document students' conceptual difficulties to all introductory physics, and to evaluate the impacts of reformed teaching practices on student understanding [41-43]. The FCI is administered as a paper and pencil test which students have $30 \mathrm{~min}$ to complete. The FCI is given as a pretest and post-test, with the pretest given during the first week of the semester, and the post during the final week of the semester. Students' pretest and post-test scores are matched and students that do not complete either the pretest or the post-test have been excluded from the analyses for this study. The matching requirement may lead to artificially high scores in 
the lecture-format classes, as lecture-format classes have substantially lower retention rates. The FCI has been given to every MI class during the last five years, totaling 11 classes, with 258 students completing both the pre- and the post-test. The FCI has been administered in lecture-format physics classes since Fall 2004. The participation of lecture-format faculty in this study has grown from 1 section in 2004 to all introductory physics sections (3) in Fall 2008. Over the course of this study we have had participation by 18 lectureformat classes and 758 matched students.

In addition to collecting matched FCI data for these students, we were able to retrieve gender and ethnicity data through the university database system as well as SAT I-Math scores for a majority of students $(88 \%)$. FIU collects self-reported gender and ethnicity data for incoming students. Students select from one of six ethnic categories (Asian, Black, Hispanic, Native American, White, Not Reported) and one of three gender categories (Female, Male, Not Reported). Of these six ethnic categories, Native American, Black, and Hispanic students have been historically under-represented in physics while Asian and White students form the majority of the students in physics, therefore in the analyses we have grouped students according to their historic representation in physics, Under-represented (UR) and Majority (MAJ).

The data considered in this paper are the preinstruction FCI \%, postinstruction FCI \%, and Raw Gain (Post \%-Pre $\%$ ) which can be interpreted as the amount students learn during the semester. We have not used normalized gain, or Hake gain, as a measure in this study; raw gain is a more transparent measure to reflect equity across samples within a single population because it does not compensate for different pre scores, which exist in cases of inequality. In order to evaluate the impacts of MI on student learning, independent samples $t$ tests were used to compare group means, using FCI Pre, FCI Post, and Raw Gain as the dependent variables and the instructional approach (Modeling or lecture-format) as the independent variable. All data were then split, first according to ethnic representation ( $\mathrm{UR}=$ under-represented or $\mathrm{MAJ}=$ majority) and then gender $(\mathrm{F}=$ Female, $\mathrm{M}=$ Male $)$, and independent samples $t$ tests were used to compare mean scores between instructional treatments and equivalent comparison groups (for example Female MI students to Female lecture-format students).

Having addressed the impacts of MI as compared with lecture-format instruction, we examined the role MI played within different under-represented groups to address the question, "Is MI equitably supportive of conceptual development for all students?" To do this the MI data were disaggregated, again using representation (under-represented or majority) and then gender. Two-way Analyses of Variance (ANOVA) were used to compare mean scores on FCI Pre, FCI Post, and Raw Gain within MI based on the representation and gender. After finding significant differences on Post FCI scores within MI students based on gender and on representation, two successive one-way Analyses of Covariance were completed to determine if the differences are due to preinstructional preparation. $88 \%$ of Modeling students had a SAT I-Math score, and SAT I-Math has been used elsewhere as a covariate related to high school preparation $[12,43]$. Af- ter running Analyses of Covariance (ANCOVA) we found that SAT I-Math scores accounted for the differences between under-represented and majority ethnic groups, but did not account for differences based on gender.

\section{Odds of success in introductory physics as an indicator of equity and participation}

We utilize students' odds of success in introductory physics as indicators of participation and equity. Odds of success are calculated as the ratio of students earning a grade of $\mathrm{C}$ - or better to those receiving $\mathrm{D}+$ or lower including Drops and Withdraws. Student grade data from the same time period of the FCI data, Fall 2004-Fall 2008 were collected from the university database. The first level analysis involves comparison between students in $\mathrm{MI}$ and lecture-format through a simple $\chi^{2}$ test for independence, effect size was established through odds ratios and confidence intervals on the odds ratios were also calculated. Again to establish measures of equity within each treatment, the data were disaggregated according to gender and ethnic representation and a second round of $\chi^{2}$ analyses were conducted.

\section{B. Results}

\section{Modeling Instruction supports all students}

(a) Evaluating support through conceptual understanding. The primary focus of this study was to evaluate the impacts of MI on the participation of all students, with special attention paid to historically under-represented groups. The results in this regard are dramatic and clear: the MI treatment produces significantly higher FCI scores than the lectureformat treatment overall, as well as across all underrepresented groups as seen in Table I.

These data, comparing Modeling Instruction and lecture, indicate that significant differences exist between the treatments on all post instruction measures (Post \%, and Raw Gain \%) while on Pre \% no significant differences exist. These results suggest that students have similar conceptual understanding upon entering Introductory Physics, but Modeling Instruction produces improved conceptual understanding after one semester (see Fig. 3). It is noteworthy that these main effects are consistent with existing published FCI studies at majority institutions that indicate reformed teaching produces increased conceptual understanding, which remains true in the context of FIU's ethnically diverse population. Other noteworthy data include the prescore which is lower at FIU than at majority universities [41], this likely indicates that students at FIU are less adequately prepared than their counterparts at majority universities.

After finding significant differences between instructional treatments on the overall data, the data were disaggregated according first to ethnic representation, and then according to gender. A second set of $t$ tests were conducted to identify differences between group means, and again all groups showed significant differences between Modeling Instruction and lecture-format instruction as can be seen in Table I. Cohen's $d$ (the effect size) for the gains in each comparison, and the $95 \%$ confidence interval on the effect size indicate that 
TABLE I. Comparison of Students in Lecture-format and MI Introductory Physics on Force Concept Inventory Disaggregated by Gender and Ethnic Representation.

\begin{tabular}{|c|c|c|c|}
\hline & FCI Pre (SE) & FCI Post (SE) & Gain (SE) \\
\hline \multicolumn{4}{|c|}{ Overall } \\
\hline Lec. $(N=758)$ & $33.1(0.6)$ & $47.9(0.7)$ & $14.8(0.5)$ \\
\hline $\operatorname{Mod}(N=258)$ & $31.5(1.0)$ & $61.9(1.3)$ & $30.4(1.1)$ \\
\hline$t$ stat, $p$ value & $t=1.4, \quad p=0.162$ & $t=9.8, \quad p<0.001^{*}$ & $t=14.1, p<0.001^{*}$ \\
\hline Cohen's d (C.I) & $-0.10(-0.24-0.04)$ & $0.71(0.57-0.86)$ & $1.05(0.90-1.20)$ \\
\hline \multicolumn{4}{|c|}{ Female } \\
\hline Lec. $(N=220)$ & $25.8(0.8)$ & $38.3(1.0)$ & $12.5(0.9)$ \\
\hline $\operatorname{Mod}(N=115)$ & $25.1(1.2)$ & $50.7(1.7)$ & $25.6(1.5)$ \\
\hline$t$ stat, $p$ value & $t=0.5, p=0.625$ & $t=6.7, p<0.001^{*}$ & $t=8.1, p<0.001^{*}$ \\
\hline Cohen's d (C.I) & $-0.06(-0.28-0.17)$ & $0.77(0.54-1.00)$ & $0.91(0.68-1.15)$ \\
\hline \multicolumn{4}{|c|}{ Male } \\
\hline Lec. $(N=538)$ & $36.1(0.7)$ & $51.8(1.6)$ & $15.8(0.7)$ \\
\hline $\operatorname{Mod}(N=143)$ & $36.6(1.5)$ & $70.9(1.6)$ & $34.2(1.4)$ \\
\hline$t$ stat, $p$ value & $t=0.4, \quad p=0.711$ & $t=10.4, \quad p<0.001^{*}$ & $t=12.6, \quad p<0.001^{*}$ \\
\hline Cohen's d (C.I) & $0.03(-0.15-0.021)$ & $0.56(0.37-0.75)$ & $1.13(0.93-1.32)$ \\
\hline \multicolumn{4}{|c|}{ Majority } \\
\hline Lec. $(N=166)$ & $34.3(1.4)$ & $48.6(1.6)$ & $14.3(1.1)$ \\
\hline $\operatorname{Mod}(N=55)$ & $36.7(2.6)$ & $68.7(2.9)$ & $32.2(2.3)$ \\
\hline$t$ stat, $p$ value & $t=0.9, \quad p=0.385$ & $t=6.3, p<0.001^{*}$ & $t=7.7, \quad p<0.001^{*}$ \\
\hline Cohen's d (C.I) & $0.13(-0.17-0.44)$ & $0.96(0.64-1.28)$ & $1.20(0.87-1.52)$ \\
\hline \multicolumn{4}{|c|}{ Under-represented } \\
\hline Lec. $(N=585)$ & $32.7(0.6)$ & $47.7(0.8)$ & $15.0(0.6)$ \\
\hline Mod $(N=199)$ & $29.8(1.1)$ & $59.8(1.4)$ & $30.0(1.2)$ \\
\hline$t$ stat, $p$ value & $t=2.3, p=0.019^{*}$ & $t=11.8, \quad p<0.001^{*}$ & $t=11.8, \quad p<0.001^{*}$ \\
\hline Cohen's d (C.I) & $-0.2(-0.36--0.003)$ & $0.62(0.46-0.79)$ & $0.99(0.82-1.16)$ \\
\hline
\end{tabular}

effect of instructional type are all large effects [44].

These data, both the overall comparison as well as the disaggregated comparisons, support our first level hypothesis that MI supports the conceptual development of all students as compared with lecture-format instruction. The significant differences across all these different groups in post-test FCI and Raw Gain indicate that the MI approach benefits all students.

(b) Evaluating support through the odds of success. Conceptual understanding results clearly indicate the benefits of Modeling Instruction over lecture-format instruction, how-

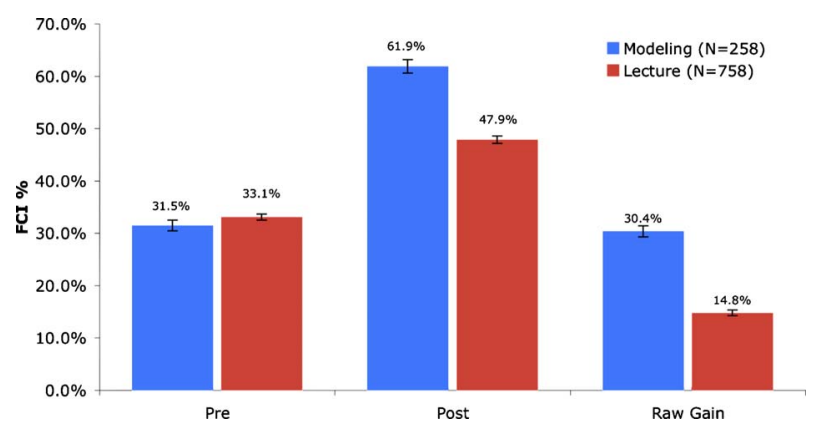

FIG. 3. (Color) Matched FCI Scores for MI and Lecture Classes. ever conceptual understanding alone is inadequate to corroborate claims of MI supporting all students. Success odds provide a more robust picture of the equity and participation resulting from MI. Odds of success are the ratio of students succeeding (earning a $\mathrm{C}-$ or better) to those not succeeding (earning a D+ or lower, including Drops, and Withdraws). A $\chi^{2}$ test for independence indicates a significant association between instructional format and odds of success, $\chi^{2}(1, n$ $=2824)=147.2, p<0.001$. The odds of succeeding in MI (7.5:1) were significantly higher than the odds of succeeding in lecture instruction (1.1:1). The odds of success in MI over lecture are measured using the odds ratio (odds ratio $=6.73$ ). The odds ratio is a form of effect size where a value of 1.0 indicates no effect. We also calculate the $95 \%$ confidence interval on the odds ratio, 4.76-9.53, indicating a large effect of MI on the odds of success for all students. These data in concert with the measures of conceptual understanding indicate that MI has established an environment that is considerably more supportive of all student success than lectureformat instruction.

\section{Evaluating equity in Modeling Instruction through the FCI}

Upon satisfying our notion that the MI environment supports conceptual learning for all students, including those from historically under-represented groups, we address the 
TABLE II. Analysis of Variance on Students in MI's FCI Scores.

\begin{tabular}{lccc}
\hline \hline & FCI Pre $(\mathrm{SE})$ & FCI Post $(\mathrm{SE})$ & Gain $(\mathrm{SE})$ \\
\hline \multicolumn{4}{c}{ Gender } \\
Female $(N=115)$ & $25.1(1.2)$ & $50.7(1.7)$ & $25.6(1.5)$ \\
Male $(N=143)$ & $36.6(1.5)$ & $70.9(1.6)$ & $34.2(1.4)$ \\
$F$-stat, $p$ value & $F=9.6, p=0.002^{* *}$ & $F=31.5, p<0.001^{* *}$ & $F=9.8, p=0.002^{* *}$ \\
$\eta^{2}\left(\right.$ C.I. on $\left.\eta^{2}\right)$ & $0.036(0.005-0.090)$ & $0.109(0.047-0.183)$ & $0.037(0.005-0.091)$ \\
& \multicolumn{2}{c}{ Ethnic Representation } \\
MAJ. $(N=55)$ & $36.7(2.6)$ & $68.7(2.9)$ & $32.2(2.3)$ \\
UR $(N=199)$ & $29.8(1.1)$ & $59.8(1.4)$ & $30.0(1.2)$ \\
$F$-stat, $p$ value & $F=7.6, p=0.006^{* *}$ & $F=8.2, p=0.004^{* *}$ & $F=0.6, p=0.439$ \\
$\eta^{2}\left(\right.$ C.I. on $\left.\eta^{2}\right)$ & $0.029(0.002-0.081)$ & $0.032(0.003-0.084)$ & $0.002(0.000-0.028)$ \\
\hline \hline
\end{tabular}

question, "Is Modeling equitably supportive of conceptual understanding for all students?" We conducted three, twoway ANOVA with gender and ethnic representation as the independent variables and FCI Pre, FCI Post, and Raw Gain as the dependent variables in subsequent ANOVAs. The results of these ANOVAs are reported in Table II.

(a) The gender gap widens in Modeling Instruction. Within the MI group, an ANOVA indicates that significant differences exist between Males and Females on the FCI, both prior to instruction and after instruction. Additionally, raw gains are significantly different (favoring males), indicating that MI widens the understanding gap on FCI scores that exists between men and women prior to instruction (see Fig. 4). Effect sizes corroborate this finding, indicating that the gender differences are small for Pre FCI and Raw Gain, but moderate for FCI Post [44].

(b) Modeling Instruction is an equitable treatment for ethnic representation. The ANOVA results reported in Table II indicate that ethnic representation accounts for significant differences in FCI Pre and FCI post scores between underrepresented and majority students (Fig. 5). However, the lack of significant differences on raw gain indicates that these differences are likely the result of preinstruction preparation.

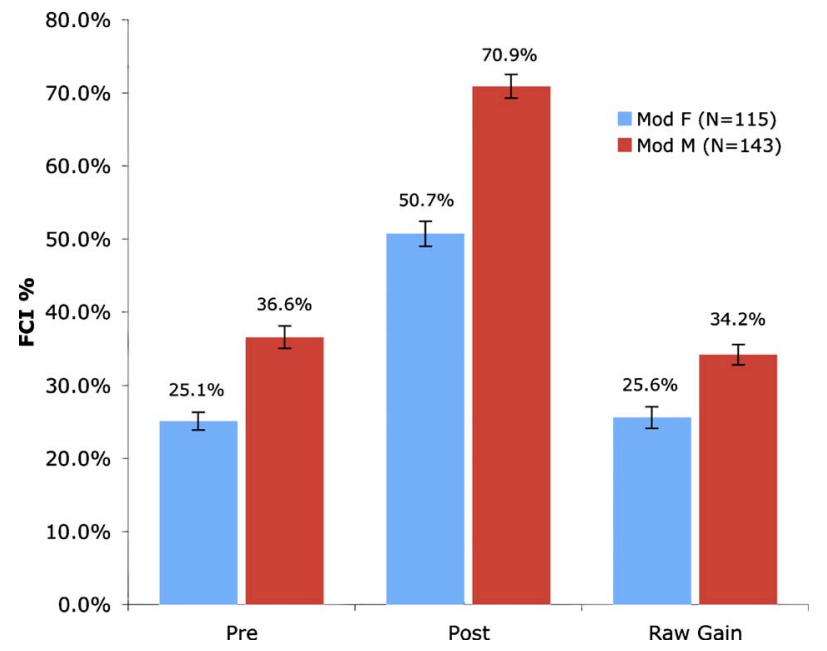

FIG. 4. (Color) FCI scores in Modeling Instruction disaggregated by gender.
Additionally, the effect sizes for the differences on FCI Pre and Post are small, again using Cohen's criteria for $\eta^{2}$ [44].

(c) Using Analysis of Covariance to account for preinstruction differences on post FCI. The two-way ANOVAs for gender and representation identified significant differences on both independent variables. In an effort to account for differences that exist prior to instruction two separate oneway ANCOVAs were conducted, using gender and representation as the independent variables, FCI Post as the dependent variable, and SAT I-Math score as a covariate. SAT I-Math has been identified by researchers at University of Colorado [43] as a covariate that accounts for a significant amount of variance in FCI scores at their institution. The results of our one-way analysis of covariance using gender as the independent variable, show that after adjusting for preinstruction SAT I-Math scores, significant differences between men and women exist on FCI Post: $F(1,227)=46.353, p$ $<0.001$, partial $\eta^{2}=0.170,95 \%$ confidence interval limits from 0.09 to 0.26 . These differences are medium to large, as indicated by the confidence interval on the effect size, which means the differences on FCI between men and women FCI scores after MI are greater than prior to instruction even when adjusting for preinstruction preparation.

Results from the second one-way ANCOVA using ethnic representation as the independent variable, show that after

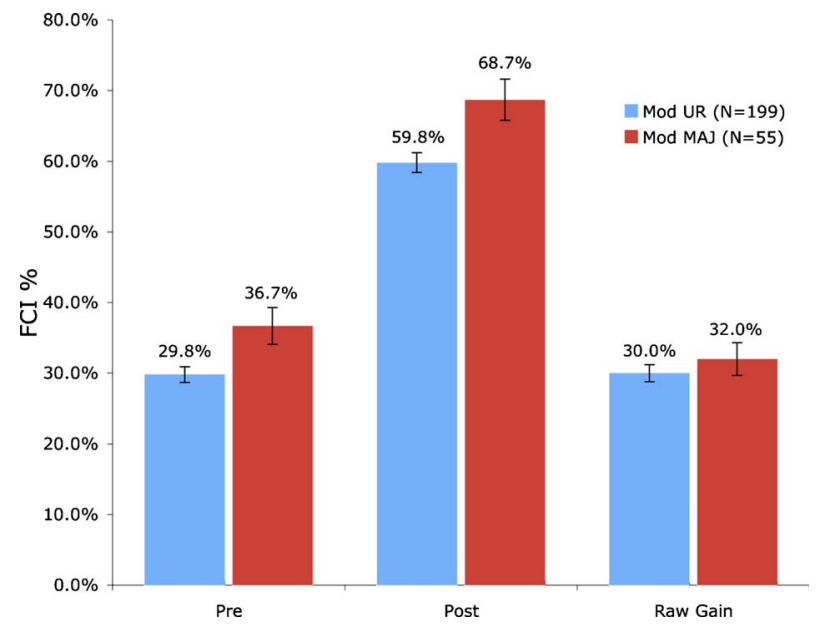

FIG. 5. (Color) FCI Scores in MI disaggregated by ethnic representation. 
TABLE III. $\chi^{2}$ test of independence on students in MI's odds of success (succeeding over not succeeding).

\begin{tabular}{lccc}
\hline \hline & Odds of Success & $\chi^{2}$ (d.f., $\left.N\right)$ & $\begin{array}{c}\text { Odds Ratio (95\% Confidence } \\
\text { Interval on Odds Ratio) }\end{array}$ \\
\hline Female $(N=143)$ & $6.15: 1$ & Gender & \\
Male $(N=180)$ & $9: 1$ & $\chi^{2}(1,323)=1.22 ;$ & $p=0.269$ \\
MAJ. $(N=55)$ & $9.8: 1$ & Ethnic Representation & $(0.35-1.35)$ \\
UR $(N=199)$ & $7.3: 1$ & $\chi^{2}(1,321)=0.42 ;$ & 0.74 \\
\hline \hline
\end{tabular}

adjusting for preinstruction SAT I-Math scores, no significant differences on FCI Post between under-represented and majority students, $F(1,225)=0.639, \quad p=0.425$, partial $\eta^{2}$ $=0.003,95 \%$ confidence interval limits from 0.00 to 0.01 . The confidence interval on the effect size suggests that in terms of ethnic representation in physics, MI does not increase the gap in preinstruction FCI scores. This finding is consistent with the lack of significant differences in Raw Gain.

\section{Evaluating equity in Modeling Instruction through odds of success}

Having addressed differences between lecture-format and Modeling Instruction on success odds for all students, again we disaggregated the data to look at odds of success as an indicator of equity through participation within MI. Table III summarizes the results of $\chi^{2}$ tests for independence on student success for both gender and ethnic representation within MI.

These results, both the $\chi^{2}$ analysis and the confidence interval on the odds ratio crossing 1.0, indicate no significant association in odds of success for gender or ethnic representation. Thus, the odds of succeeding in Modeling are equitably likely regardless of gender or ethnic representation.

\section{DISCUSSION}

(A) Modeling Instruction creates an inclusive environment supportive of all students

This research used two measures of student performance as indicators of the role of Modeling Instruction on establishing an inclusive learning environment that is supportive of conceptual development and enhanced participation for historically under-represented students in physics. When compared with lecture-format instruction, the evidence reported in Table I strongly supports the hypothesis that MI provides a more supportive environment for conceptual development for all students. We further supported this claim by providing data on the odds of success, which show that for students in Modeling Instruction the odds of succeeding are 6.73 times greater than for students in lecture-format classes. These results indicate meaningful differences in the way that MI and lecture-format instruction transform the participation of students. The MI environment impacts student conceptual development by means of a pedagogy which helps students transform their participation toward that of practicing physicists through collaborative interactions among students, active participation in the creation of models, and extensive use of representational tools in problem solving. This conclusion is further strengthened by considering our previously reported results indicating that MI students increase their favorable attitudes about physics and physics learning as measured by the CLASS instrument, the first reported measurement in an introductory physics course [45]. Incorporating these results into a coherent framework, we find that Modeling Instruction establishes an inclusive learning environment supportive of all students.

The impacts on student conceptual understanding we document are consistent with existing research on improving student understanding as well as established theory on supporting under-represented groups. Our research has provided one of the most extensive quantitative studies of impacts of educational reforms at a HSI. The consistency between our results and investigations of reforms at majority institutions [41] indicates that lessons learned from other reforms are applicable at HSIs and with historically under-represented populations. One outcome of these results is that reforms seem to work consistently across a variety of historically under-represented groups and; therefore, the implementation of reforms are one approach to establishing an inclusive learning environment. Finally, conducting this research has generated a substantial data set on conceptual learning with a unique population, which provides baseline data about not only the reformed classes, but also with lecture-format taught students which does not exist elsewhere.

\section{Modeling Instruction supports an equitable transformation of participation}

Considerable debate exists on the role and interpretation of understanding or learning gaps [46-48]. An equity of outputs view maintains that closing gaps is an equitable treatment, but this inherently means one group gains more than another. An equity of treatment view holds that maintaining gaps is an equitable treatment, as then all students gain the same, but this inherently leaves unequal groups. A third view maintains that one should not invest in looking at gaps and should instead focus on excellence of students [46]. Our research affords the opportunity to look at both conceptual understanding differences over time but also to look at how 
students are retained within the MI environment, together these opportunities will establish how students from different groups transform their participation within the Modeling environment.

\section{Modeling Instruction supports equitable participation by ethnic representation}

Our study identifies that a preinstruction conceptual understanding gap exists between students from majority groups and under-represented ethnic groups. This understanding gap is maintained after instruction; using an ANOVA on Raw Gain and an ANCOVA on FCI Post we found that these differences are largely attributable to preinstruction preparation, which leads to the conclusion that Modeling Instruction equitably supports conceptual development for students from majority groups and underrepresented ethnic groups from an equity of treatment perspective. In support of this finding we also have shown that students from majority and under-represented groups have a statistically indistinguishable odds of success in the MI classes. Combined, these measures tell a coherent story, but remain incomplete, as broader equity in physics requires equitable levels of participation in physics broadly, including graduation rates, leadership roles, and participatory roles within the learning community. Additionally, attention should be paid to precollege instruction, as the gaps which exist prior to instruction at FIU indicate an inequity within the educational system. The result that differences in prescores and postscores are attributable to preinstruction preparation, in conjunction with the fact that the FCI Pre scores at FIU are markedly lower than those reported at majority universities [41] leads to the reasonable conclusion that students at FIU, who primarily come from ethnically diverse South Florida, are systematically disadvantaged in terms of precollege preparation in physics. This conclusion is consistent with the work of Kelly [49] who found that students in New York City have unequal levels of access to physics in high school which leads to preinstruction learning gaps at the university level. Kelly links the systemic inequality of access within urban settings to socioeconomic factors as well as ethnic makeup of schools [50].

\section{Modeling Instruction yields mixed results for equitable participation by gender}

Our data show that Modeling Instruction is equitable, both from an equity of treatment perspective with respect to conceptual development and from an equity of outputs perspective in regard to odds of success for majority and underrepresented ethnic groups. However, the data considering gender are mixed. First, the preinstruction conceptual understanding gap widens in MI. Though the MI environment is clearly more supportive than lecture-format instruction, because the conceptual understanding gap is growing, we cannot conclude that MI equitably supports conceptual development for males and females. This conclusion is dismaying, but as we have established, it would be a mistake to utilize only one measure to evaluate the overall supportiveness of the learning environment. From a participationist view on learning the ongoing inclusion of women in the discipline of physics is a better marker (albeit harder to measure) of an equitable learning environment. Odds of success, is one such measure of participation, which our research has shown indicates an equitable environment for women. To better understand the complex educational system, we must turn to additional measures, including measures of persistence, affective measures, and other markers of success to more thoroughly evaluate the equity inherent in the learning environment.

In addition to considering other measures that evaluate supportiveness of the environment, other challenges to the conclusions drawn here should be raised, including the validity of the FCI as an instrument. While the FCI is a standard instrument and is widely used in physics education research, McCullough identifies potential sources of gender bias in the FCI [51]. Although a potential bias of the instrument would perhaps raise suspicion of the results, bias alone does not sufficiently address the point that the bias would remain constant, both before and after instruction, and because we are showing a widening of the gender gap the conclusion would remain.

Another consideration is that through the ongoing interactive aspects of MI, other factors that contribute to persistence, such as self-efficacy and sense of community, are being nurtured in students. Self-efficacy is defined to be the beliefs in one's ability to perform a specific task, particularly emphasizing the specificity of the task [52]. Studies have shown that self-efficacy and retention in technical fields are related [53-58]. Yet to be thoroughly explored, however, is the impact of reformed teaching approaches in physics on students' self-efficacy. Results from a study on nonmajor physics classes suggests that teaching strategies have a significant effect on the self-efficacy of students [59]. A study is underway at FIU to examine the impact of self-efficacy and its possible compensation for the widening of the conceptual understanding gender gap in relation to participation in physics.

\section{CONCLUSION}

Physics Education Research has an extensive history of research motivated curriculum development. Many of these curricula have been shown to impact students' conceptual development. Further analyses and implementations may reveal additional benefits including equity across student groups, and encouraging further participation in science. Education reform plays a valuable role in efforts to establish an overall supportive learning environment for underrepresented students in physics by improving conceptual development for all students. However, it also raises issues of equity in the reform, as historically under-represented students arrive at university physics with different conceptual understanding. In terms of ethnic representation, precollege preparation accounts for these differences in conceptual understanding. Gender differences are not accounted for by precollege preparation alone. In this paper, we have shown how Modeling Instruction provides a supportive learning environment and substantiated this finding with multiple indi- 
cators. These indicators document both the conceptual development of students and the persistence within the Modeling course. These conclusions lead to further research projects which are in the planning phases or already underway to expand understanding of characteristics of introductory physics course that supports the participation of underrepresented students. The first research project, which is underway, is an examination of the long-term persistence of students in MI and lecture-format classes to identify lasting impacts of the MI classes. Following this project is a study of the impacts of reformed teaching on self-efficacy as a way to reconcile the existence of gender differences in conceptual learning, with the lack of difference in retention. Finally, a research effort directed at investigating extracurricular influences on students' participation in physics shifts the research toward a more comprehensive view of supportive environments. The results presented in this paper demonstrate the need to assess research driven curriculum development projects and to assess their impacts on equity and participation.

\section{ACKNOWLEDGMENTS}

The authors would like to thank the Physics Education Research Group at FIU and Jeff Saul for their efforts at data collection and the Noobs for their invaluable feedback. This research is supported by the National Science Foundation Grants No. 0312038 and No. 0808214, and the FIU PhysTEC project.
[1] American Recovery and Reinvestment Act of 2009, Public Law 111-5, 111th Cong., 1st. session. (February 17, 2009).

[2] National Science Foundation, Division of Science Resources Statistics., Detailed Statistical Tables NSF 08-321, in Science and Engineering Degrees: 1966-2006. (Arlington, VA, 2008). Available at: http://www.nsf.gov/statistics/nsf08321/

[3] J. Gainen, Barriers to success in quantitative gatekeeper courses, N. Dir. Teach. Learn. 1995, 5.

[4] P. J. Mulvey and S. Nicholson, Enrollments and Degrees Report, 2006, R-151.43, (2008).

[5] B. Obama, "Remarks at National Academy of Sciences Annual Meeting" National Academy of Sciences, Washington, DC, (April 27, 2009).

[6] H. Mehan and L. Hubbard, “Tracking 'untracking': Evaluating the effectiveness of an educational innovation," Center for Research on Education, Diversity \& Excellence Research Brief \#3, (1999).

[7] M. M. Atwater, in Handbook of Research in Science Teaching and Learning, edited by D. L. Gabel (Macmillan, New York, NY, 1994), pp. 558-576.

[8] D. Hestenes, M. Wells, and G. Swackhamer, Force concept inventory, Phys. Teach. 30, 141 (1992).

[9] M. Lederman, Gender/InEquity in science education: A response, J. Res. Sci. Teach. 40, 604 (2003).

[10] P. M. Sadler and R. H. Tai, Success in introductory college physics: The role of high school preparation, Sci. Educ. 85, 111 (2001).

[11] D. R. Baker, in International Handbook of Science Education, edited by K. G. Tobin and B. J. Fraser (Kluwer Academic Publishers, Dordrecht, Netherlands, 1998).

[12] H. C. Waxman, Y. N. Padron, and A. Garcia, in Narrowing the achievement gap: Strategies for educating Latino, Black, and Asian students, edited by S. J. Paik and H. J. Walberg (Springer, 2007).

[13] J. Handelsman, D. Ebert-May, R. Beichner, P. Bruns, A. Chang, R. DeHaan, J. Gentile, S. Lauffer, J. Stewart, S. M. Tilghman, and W. B. Wood, Scientific teaching, Science 304, 521 (2004).

[14] R. H. Barba and K. E. Reynolds, in International Handbook of Science Education, edited by K. G. Tobin and B. J. Fraser
(Kluwer Academic Publishers, Dordrecht, Netherlands, 1998).

[15] N. Finkelstein, Learning Physics in Context: A study of student learning about electricity and magnetism, Int. J. Sci. Educ. 27, 1187 (2005).

[16] A. F. Cabrera, J. L. Crissman, E. M. Bernal, A. Nora, P. T. Terenzini, and E. T. Pascarella, Collaborative learning: Its impact on college students' development and diversity, J. Coll. Student Dev. 43, 20 (2002).

[17] M. B. Baxter Magolda, Knowing and reasoning in college: Gender-related patterns in students' intellectual development (Jossey-Bass, San Francisco, 1992).

[18] M. F. Belenky, B. M. Clinchy, N. Goldberger, and J. M. Tarule, Women's ways of knowing: The development of self, voice and mind (Basic Books, New York, 1986).

[19] M. A. Lundeberg and S. D. Moch, Influence of social interaction on cognition: Connected learning in science, J. Higher Educ. 66, 312 (1995).

[20] A. Martinez-Aleman, Understanding and investigating female friendship's educative value, J. Higher Educ. 68, 119 (1997).

[21] D. W. Johnson, R. T. Johnson, and K. A. Smith, "Cooperative learning: Increasing college faculty instructional productivity" (ASHE-ERIC Higher Education Report No. 4) Washington, DC: George Washington University, School of Education and Human Development. (1991).

[22] V. Tinto, Classrooms as communities: Exploring the educational character of student persistence, J. Higher Educ. 68, 599 (1997).

[23] J. Kulik and C. L. Kulik, in “College teaching," in Research on teaching: Concepts findings and implications, edited by $\mathrm{P}$. Peterson and H. Walberg (McCutcheon, Berkeley, CA, 1979).

[24] S. J. Lynch, Equity and Science Education Reform (Earlbaum, New Jersey, 2000).

[25] O. Lee and A. Luykx, in Handbook of Research in Science Education, edited by S. K. Abell and N. G. Lederman (Erlbaum, Mahwah, NJ, 2007), pp. 171-197.

[26] Z. Hazari, R. Tai, and P. Sadler, Gender differences in introductory university physics performance: The influence of high school physics preparation and affective factor, Sci. Educ. 91, 847 (2007).

[27] G. J. Kelly, in Handbook of Research on Science Education, 
edited by S. K. Abell and N. G. Lederman (Erlbaum, Mahwah, NJ, 2007), pp. 443-469.

[28] A. Sfard, On two metaphors for learning and the dangers of choosing just one, Educ. Res. 27, 4 (1998).

[29] A. Sfard, Moving between discourses: From learning-asacquisition to learning-as-participation, in 2009 Physics Education Research Conference, edited by M. Sabella, C. Henderson, and C. Singh, AIP Conf. Proc. No. 1179 (AIP, New York, 2009), p. 55.

[30] J. Lave and E. Wenger, Situated Learning: Legitimate peripheral participation (Cambridge University Press, Cambridge, UK, 1991).

[31] B. Rogoff, E. Matusov, and C. White, in "Models of Teaching and Learning: Participation in a Community of Learners," in The Handbook of Education and Human Development: New Models of Learning, Teaching, and Schooling, edited by D. R. Olson and N. Torrance (Blackwell Publishing Ltd, Malden, MA, 1996), pp. 388-414.

[32] E. Wenger, Communities of practice: Learning, meaning and identity (Cambridge University Press, Cambridge, England, 1998).

[33] A. Sfard, When the rules of discourse change, but nobody tells you: Making sense of mathematics learning from a commognitive standpoint, J. Learn. Sci. 16, 565 (2007).

[34] D. Hestenes and J. Jackson, ASU Modeling Workshop Project Report Reference, 2000.

[35] D. Hestenes, Toward a modeling theory of instruction, Am. J. Phys. 55, 440 (1987).

[36] E. Brewe, Modeling theory applied: Modeling instruction in introductory physics, Am. J. Phys. 76, 1155 (2008).

[37] D. M. Desbien, Ph.D. Unpublished Dissertation, Arizona State University, 2002.

[38] Hispanic Outlook Magazine, May 5, 2009.

[39] FIU Office of Planning and Institutional Effectiveness, Florida International University institutional research Factbook, 2008.

[40] M. Lorenzo, C. H. Crouch, and E. Mazur, Reducing the gender gap in the physics classroom, Am. J. Phys. 74, 118 (2006).

[41] R. R. Hake, Interactive-engagement versus traditional methods: A six-thousand-student survey of mechanics test data for introductory physics courses, Am. J. Phys. 66, 64 (1998).

[42] D. Sawada, M. D. Piburn, E. Judson, J. Turley et al., Measuring reform practices in science and mathematics classrooms: The reformed teaching observation protocol, Sch. Sci. Math. 102, 245 (2002).

[43] L. Kost, S. J. Pollock, and N. D. Finkelstein, Characterizing the gender gap in introductory physics, Phys. Rev. ST Phys. Educ. Res. 5, 010101 (2009).

[44] J. Cohen, Statistical Power Analysis for the Behavioural Sci- ences (Erlbaum, New York, 1988).

[45] E. Brewe, L. Kramer, and G. O'Brien, Modeling instruction: Positive attitudinal shifts in introductory physics measured with CLASS, Phys. Rev. ST Phys. Educ. Res. 5, 013102 (2009).

[46] R. Gutierrez, A "gap gazing" fetish in mathematics education? Problematizing research on the achievement gap, J. Res. Math. Educ. 39, 357 (2008).

[47] A. J. Rodriguez, From gap gazing to promising: Moving toward equity in urban education reform, J. Res. Sci. Teach. 38, 1115 (2001).

[48] J. S. Eccles, Gender-roles and Women's achievement, Educ. Res. 15, 15 (1986).

[49] A. Kelly, Issues of equity in physics access and enrollment in New York City public high schools (A), J. Acoust. Soc. Am. 122, 2986 (2007).

[50] A. Kelly and K. Sheppard, Secondary school physics availability in an urban setting: Issues related to academic achievement and course offerings, Am. J. Phys. 77, 902 (2009).

[51] L. McCullough, Gender, context, and physics assessment, J. Int. Women's Stud. 5, 20 (2004).

[52] A. Bandura, Self-efficacy: Toward a unifying theory of behavioral change, Psychol. Rev. 84, 191 (1977).

[53] N. E. Betz and G. Hackett, The relationship of career-related self-efficacy expectations to perceived career options in college women and men, J. Couns. Psychol. 28, 399 (1981).

[54] N. E. Betz and K. K. Voyten, Efficacy and outcome expectations influence career exploration and decidedness, Career Dev. Q. 46, 179 (1997).

[55] R. W. Lent, S. D. Brown, and K. C. Larkin, Self-efficacy in the prediction of academic performance and perceived career options, J. Couns. Psychol. 33, 265 (1986).

[56] R. W. Lent, Comparison of three theoretically derived variables in predicting career and academic behavior: Selfefficacy, interest congruence, and consequence thinking, J. Couns. Psychol. 34, 293 (1987).

[57] G. Hackett and R. W. Lent, in Handbook of Counseling Psychology, 3rd ed., edited by S. D. Brown and R. W. Lent (Wiley, New York, NY, 1992), pp. 419-452.

[58] R. T. Lapan, P. Shaughnessy, and K. Boggs, Efficacy expectations and vocational interests as mediators between sex and choice of math/science college majors: A longitudinal study, J. Vocat Behav. 49, 277 (1996).

[59] H. Fencl and K. Scheel, Engaging students: An examination of the effects of teaching strategies on self-efficacy and course climate in a nonmajors physics course, J. Coll. Sci. Teach. 35, 20 (2005). 